\title{
Low Nanogram Per Liter Determination of Halogenated Nonylphenols, Nonylphenol Carboxylates, and Their Non-Halogenated Precursors in Water and Sludge by Liquid Chromatography Electrospray Tandem Mass Spectrometry
}

\author{
M. Petrovic and D. Barceló \\ Department of Environmental Chemistry, IIQAB-CSIC, Barcelona, Spain
}

\author{
A. Diaz and F. Ventura \\ AGBAR, Barcelona, Spain
}

\begin{abstract}
A new LC-MS-MS method for quantitative analysis of nonylphenol (NP), nonylphenol carboxylates (NPECs), and their halogenated derivatives: brominated and chlorinated nonylphenols $(\mathrm{BrNP}, \mathrm{ClNP})$, brominated and chlorinated nonylphenol carboxylates $\left(\mathrm{BrNPE}_{1} \mathrm{C}\right.$ and $\left.\mathrm{ClNPE}_{1} \mathrm{C}\right)$ and ethoxycarboxylates $\left(\mathrm{BrNPE}_{2} \mathrm{C}\right.$ and $\left.\mathrm{ClNPE}_{2} \mathrm{C}\right)$ in water and sludge has been developed. Electrospray negative ionization MS-MS was applied for the identification of above mentioned compounds. Upon collision-induced dissociation, their deprotonated molecules gave different fragments formed by the cleavage of the alkyl moiety and/or (ethoxy)carboxylic moiety. For halogenated compounds a highly diagnostic characteristic pattern of isotopic doublet signals was obtained and fragmentation yielded, in addition to above mentioned ions, $[\mathrm{Br}]^{-}$and $[\mathrm{Cl}]^{-}$, respectively. Quantitative analysis was done in the multiple reaction monitoring (MRM) mode, using two specific combinations of a precursor-product ion transitions for each compound. Additionally, for halogenated compounds two specific channels for each transition reaction, corresponding to two isotopes, were monitored and the ratio of their abundances used as an identification criterion. The method has been validated in terms of sensitivity, selectivity, accuracy, and precision and was applied to the analysis of water and sludge samples from drinking water treatment plant (DWTP) of Barcelona (Catalonia, NE Spain). Halogenated NP and NPECs were detected in prechlorinated water in concentrations up to $315 \mathrm{ng} / \mathrm{L}, \mathrm{BrNPE}_{2} \mathrm{C}$ being the most abundant compound. In the DWTP effluent non-halogenated compounds were detected at trace levels $(85,12$ and $10 \mathrm{ng} / \mathrm{L}$ for NP, $\mathrm{NPE}_{1} \mathrm{C}$, and $\mathrm{NPE}_{2} \mathrm{C}$, respectively), whereas concentration of halogenated derivatives never exceeded $10 \mathrm{ng} / \mathrm{L}$. Nonylphenol, brominated and chlorinated NPs were found in flocculation sludge in concentrations of 150,105, and $145 \mu \mathrm{g} / \mathrm{kg}$, respectively. Acidic polar metabolites were found in lower concentrations up to $20 \mu \mathrm{g} / \mathrm{kg}$. (J Am Soc Mass Spectrom 2003, 14, 516-527) @ 2003 American Society for Mass Spectrometry
\end{abstract}

$\mathrm{N}$ on-ionic surfactants, nonylphenol polyethoxylates (NPEOs), have been widely used in the last 40 years as detergents, emulsifiers, dispersants, antifoamers and pesticide adjuvants. The biodegradation of NPEOs under aerobic conditions yields mainly short ethoxy chain oligomers $\left(\mathrm{NPEO}_{1}\right.$ and $\mathrm{NPEO}_{2}$ ), whereas under anaerobic conditions fully de-

Published online April 2, 2003

Address reprint requests to Dr. M. Petrovic, Department of Environmental Chemistry, IIQAB-CSIC, c/Jordi Girona 18-26, 08034 Barcelona, Spain. E-mail: mpeqam@cid.csic.es ethoxylated nonylphenol (NP) is also formed. Further transformation leads to acidic metabolites formed by oxidation of the ethoxy chain (nonylphenol carboxylates; NPECs) as well as oxidation of the branched alkyl chain [1-4]. During the chlorination process at drinking water treatment plants (DWTP) [5-8] and wastewater treatment plants (WWTP) $[9,10]$ the formation of halogenated derivatives, such as ring-brominated and chlorinated NPEOs, NPECs, and NPs, have been reported.

Toxicity of NP and short ethoxy chain NPEOs to aquatic organisms [11], lipophilic properties that lead to bioaccumulation in aquatic food chain [12], and ability 
to mimic endogenous hormone $17 \beta$-estradiol $[13,14]$ are well documented. However, little is known about environmental significance and toxicology of brominated and chlorinated alkylphenolic compounds. Maki et al. [15] determined that, both BrNPEOs and BrNPECs, show higher acute toxicity to Daphnia magna than their non-brominated precursors NPEOs and NPECs. A recent study, employing recombinant yeast assay (RYA) and enzyme linked receptor assay (ELRA) for the determination of estrogenic and anti-estrogenic activity, showed that halogenated compounds retained a significant affinity for the estrogen receptors suggesting that they may be still able to disturb the hormone imbalance of exposed organisms [16]. This was especially clear for halogenated NPECs, which acted as true anti-estrogens in the RYA.

The presence of alkylphenolic compounds in the environment has become of increasing concern globally and efforts have been made to determine their concentration levels in WWTP and in aquatic environments. However, studies to date have largely focused on short chain NPEOs, NPECs, and NPs, while fewer reports have included halogenated metabolites. One of the reasons for this is the low relative abundance of these compounds (generally less than $10 \%$ of the total pool of alkylphenolic compounds) and unavailability of appropriate analytical methods for their identification and quantification.

The first attempts to analyse halogenated alkylphenolic compounds were carried out using Fast Atom Bombardment-Mass Spectrometry (FAB-MS) [5, 7, 8, 17], which proved to be a reliable tool for the identification of halogenated metabolites in raw and drinking water, but not for their quantification. Recently, some efforts have been made to quantify these compounds in complex environmental and wastewater samples. Methods applied included gas chromatography-mass spectrometry (GC-MS) [10, 18, 19] (after appropriate derivatization) and reversed-phase liquid chromatography with electrospray mass spectrometry (LC-ESI-MS) $[6,20,21]$. ESI permitted the direct determination of the full range of halogenated NPEOs metabolites (i.e., XNPEOs, XNPECs and XNPs), as well as their precursors in aqueous and solid samples, thus obviating the necessity to methylate them. However, using "soft ionization" LC-MS, under conditions giving solely molecular ions, the identification of halogenated compounds is difficult since the chlorinated derivatives $\left(\mathrm{CINPEO}_{n}\right.$ and $\mathrm{CINPE}_{n} \mathrm{C}$ ) have the same molecular mass as brominated compounds with one ethoxy group less (BrN$\mathrm{PEO}_{\mathrm{n}-1}$ and $\mathrm{BrNPE}_{\mathrm{n}-1} \mathrm{C}$ ) [6]. Moreover, in the analysis of real-world samples $\mathrm{CINPE}_{1} \mathrm{C}$ was obstructed by a severe isobaric interference of linear alkylbenzene sulfonate $\left(C_{11} L A S\right)$, which is often found in environmental and wastewater samples in concentrations several orders of magnitude higher than those of halogenated alkylphenolic compounds.

Thus, to obviate the matrix interference and interference of known and unknown compounds that may cause deviations when only a single stage of mass selectivity is used, more selective methods, such as tandem mass spectrometry are needed. However, although considered as one of the most powerful techniques for structure interpretation and quantification, LC-MS-MS has been seldom used in the analysis of acidic and neutral metabolites of NPEOs [2, 22], and has not been applied thus far to study their halogenated derivatives.

In the present work, a tandem mass spectrometric investigation of halogenated NPECs, NPs and their precursors (non-halogenated analogs) was carried out. Electrospray negative ionization MS-MS was applied for the identification of acidic and neutral NPEOs metabolites. From the observed ion fragmentation pathways a reliable and sensitive quantification method, that overcomes the main drawbacks on existing methods, is developed. The method was applied to study occurrence of halogenated alkylphenolic compounds derived from chlorination treatment in DWTP of Barcelona (Spain). To our knowledge this is the first LCMS-MS method that permits analysis of halogenated NPs and NPECs at low nanogram per liter level.

\section{Experimental}

\section{Standards and Reagents}

$\mathrm{NPE}_{1} \mathrm{C}$ and $\mathrm{NPE}_{2} \mathrm{C}$ were synthesized according to the method described elsewhere [19]. Technical grade 4-NP and 4-nonyloxy benzoic acid, used as an internal standard was obtained from Aldrich (Milwaukee, WI).

BrNP was synthesized using elemental bromine according to the method described by Reinhard et al. [9]. CINP was prepared by chlorination of nonylphenol using sulfuryl chloride according to the method of Stokker et al. [23]. $\mathrm{BrNPE}_{1} \mathrm{C}$ and $\mathrm{ClNPE}_{1} \mathrm{C}$ were synthesized by reacting brominated and chlorinated NP, respectively, with chloroacetic acid in the presence of sodium hydride and dimethylformamide as a solvent. These two synthesized compounds rendered $\mathrm{BrNPEO}_{1}$ and $\mathrm{CINPEO}_{1}$ by reduction with lithium aluminum hydride in ether solution. $\mathrm{BrNPEO}_{2}$ and $\mathrm{CINPEO}_{2}$ were synthesized by reacting BrNP and CINP, respectively, with 2-(2-chloroethoxy)ethanol in the presence of $\mathrm{NaOH}$ in water. Finally, $\mathrm{BrNPE}_{2} \mathrm{C}$ and $\mathrm{ClNPE}_{2} \mathrm{C}$ were obtained from $\mathrm{BrNPEO}_{2}$ and $\mathrm{ClNPEO}_{2}$, respectively, by oxidation with Jones reagent [9].

\section{Water Samples}

Raw water entering the DWTP Sant Joan Despí (Barcelona, Spain) and water samples after each treatment step (i.e., prechlorination, rapid sand filtration, groundwater dilution, ozonation, granulated active carbon filtration, and final chlorination) were collected as grab samples in Pyrex borosilicate amber glass containers, previously rinsed with high-purity water.

NP, NPECs, and their halogenated derivatives were 
Table 1. List of MRM channels, cone and collision energies applied to ESI-MS-MS for the analysis of nonylphenol, nonylphenol carboxylates, and their halogenated derivatives

\begin{tabular}{|c|c|c|c|c|c|c|c|}
\hline \multirow[b]{2}{*}{ Compound } & \multicolumn{3}{|c|}{ MRM 1 (Quantification) } & \multicolumn{3}{|c|}{ MRM 2 (Confirmation) } & \multirow[b]{2}{*}{$\begin{array}{c}\text { Ratio MRM1/ } \\
\text { MRM2 }\end{array}$} \\
\hline & $\begin{array}{l}\text { Precursor }(m / z) \rightarrow \\
\text { Product }(m / z)\end{array}$ & $\begin{array}{l}\text { Cone } \\
\text { (V) }\end{array}$ & $\begin{array}{c}\text { Collision } \\
(\mathrm{eV})\end{array}$ & $\begin{array}{l}\text { Precursor }(\mathrm{m} / \mathrm{z}) \rightarrow \\
\quad \text { Product }(\mathrm{m} / \mathrm{z})\end{array}$ & $\begin{array}{l}\text { Cone } \\
\text { (V) }\end{array}$ & $\begin{array}{c}\text { Collision } \\
(\mathrm{eV})\end{array}$ & \\
\hline NP & $219 \rightarrow 133$ & 30 & 30 & $219 \rightarrow 147$ & 30 & 30 & 9.2 \\
\hline BrNP & $\begin{array}{l}297 \rightarrow 79 \\
299 \rightarrow 81\end{array}$ & 30 & 30 & $\begin{array}{l}297 \rightarrow 211 \\
299 \rightarrow 213\end{array}$ & 30 & 30 & 12.3 \\
\hline CINP & $\begin{array}{l}253 \rightarrow 167 \\
255 \rightarrow 169\end{array}$ & 30 & 30 & $\begin{array}{l}253 \rightarrow 181 \\
255 \rightarrow 183\end{array}$ & 30 & 30 & 10.5 \\
\hline $\mathrm{NPE}_{1} \mathrm{C}$ & $277 \rightarrow 219$ & 10 & 30 & $219 \rightarrow 133$ & 30 & 30 & 1.8 \\
\hline $\mathrm{BrNPE}_{1} \mathrm{C}$ & $\begin{array}{l}355 \rightarrow 297 \\
357 \rightarrow 299\end{array}$ & 10 & 30 & $\begin{array}{l}355 \rightarrow 79 \\
357 \rightarrow 81\end{array}$ & 30 & 30 & 1.0 \\
\hline $\mathrm{CINPE}_{1} \mathrm{C}$ & $\begin{array}{l}311 \rightarrow 253 \\
313 \rightarrow 255\end{array}$ & 10 & 30 & $\begin{array}{l}253 \rightarrow 167 \\
255 \rightarrow 169\end{array}$ & 30 & 30 & 3.5 \\
\hline $\mathrm{NPE}_{2} \mathrm{C}$ & $219 \rightarrow 133$ & 30 & 30 & $321 \rightarrow 219$ & 10 & 30 & 1.2 \\
\hline $\mathrm{BrNPE}_{2} \mathrm{C}$ & $\begin{array}{l}297 \rightarrow 79 \\
299 \rightarrow 81\end{array}$ & 30 & 30 & $\begin{aligned} 399 & \rightarrow 297 \\
401 & \rightarrow 299\end{aligned}$ & 5 & 20 & 2.0 \\
\hline $\mathrm{CINPE}_{2} \mathrm{C}$ & $\begin{array}{l}253 \rightarrow 167 \\
255 \rightarrow 169\end{array}$ & 30 & 30 & $\begin{array}{l}355 \rightarrow 253 \\
357 \rightarrow 255\end{array}$ & 5 & 20 & 5.5 \\
\hline
\end{tabular}

isolated from water samples using solid-phase extraction (SPE). A more detailed description of the SPE method is given elsewhere [6]. Briefly, $500 \mathrm{~mL}$ of water samples were loaded onto preconditioned Accubond C18 cartridges (J and W Scientific, Folsom, CA). Cartridges were air-dried under vacuum, and were eluted with $2 \times 4 \mathrm{~mL}$ of methanol. The eluates were taken gently to dryness under a nitrogen steam and reconstituted in $500 \mu \mathrm{L}$ of methanol.

\section{Sludge Samples}

Sludge from DWTP of Barcelona, obtained from prechlorinated raw water after flocculation with aluminium sulfate and mixed in a minor proportion with sludge coming from the washing of sand filters, was collected in precleaned amber glass bottles. The suspension (concentration of dry matter 3.5 to $5 \mathrm{~g} / \mathrm{L}$ ) was centrifuged at $4500 \mathrm{rpm}$, and the solid matter was separated and frozen at $-20^{\circ} \mathrm{C}$ before being freezedried.

Pressurized liquid extractions (PLE) were carried out using a Dionex ASE 200 (Dionex, Idstein, Germany) as described elsewhere [24]. Briefly, $1 \mathrm{~g}$ sub-sample of freeze-dried sludge was mixed with $\mathrm{Na}_{2} \mathrm{SO}_{4}$ and filled into $11 \mathrm{~mL}$ extraction cells. Extraction was carried out with acetone/methanol $(1: 1, \mathrm{vol} / \mathrm{vol})$ under following conditions: temperature of $75^{\circ} \mathrm{C}$, pressure 1500 psi, heating time $5 \mathrm{~min}$, two cycles of static extraction (5 $\min )$. As a final step, the cell was purged with gaseous nitrogen. The total volume of extract was $\sim 20 \mathrm{ml}$. Extracts obtained by PLE, were concentrated to an approximate volume of $1 \mathrm{ml}$ using a rotary vacuum, redissolved in $100 \mathrm{ml}$ of HPLC water and subsequently purified by SPE using LiChrolute C18 cartridges (Merck, Darmstadt, Germany), as described elsewhere [6].

\section{Chromatographic Conditions}

Analyses were performed on a Waters 2690 series Alliance HPLC (Waters, Milford, MA) with a quaternary pump equipped with a 120 vial capacity sample management system. The analytes were separated on a narrow-bore $3 \mu \mathrm{m}, 55 \times 2 \mathrm{~mm}$ i.d. $\mathrm{C}_{18}$ reversed phase column Purospher STAR RP-18 endcapped (Merck, Darmstadt, Germany). The sample injection volume was set at $10 \mu \mathrm{L}$. A binary mobile phase gradient with methanol (A) and water (B) was used for analyte separation at a flow rate of $200 \mu \mathrm{L} / \mathrm{min}$. The elution gradient was linearly increased from $30 \% \mathrm{~A}$ to $85 \% \mathrm{~A}$ in $10 \mathrm{~min}$, then increased to $95 \% \mathrm{~A}$ in $10 \mathrm{~min}$ and kept isocratic for $5 \mathrm{~min}$.

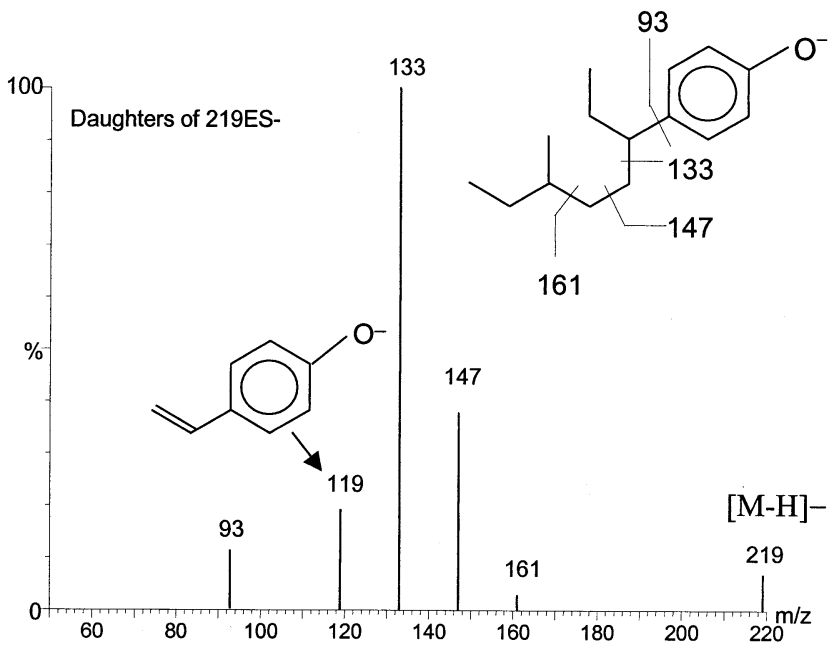

Figure 1. Product ion scan of NP with $\mathrm{m} / \mathrm{z} 219$ and the proposed fragmentation scheme under CID conditions obtained using argon as collision gas at collision energy of $40 \mathrm{eV}$. Note: The exact branching of the alkyl chain is unknown and the alkyl isomer shown here is just one of several possibilities. 


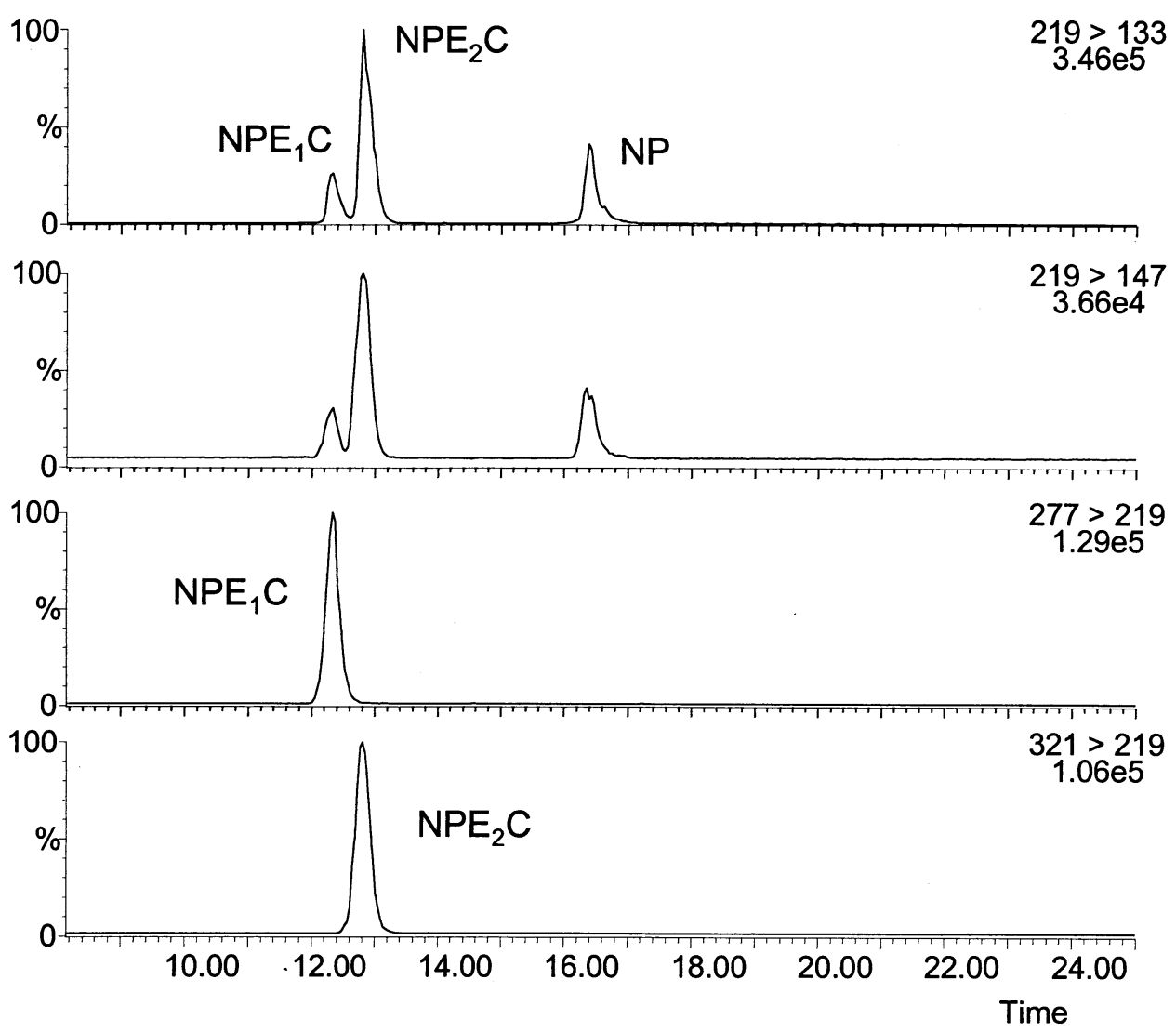

Figure 2. MS/MS chromatograms of raw effluent (river water) treated in Barcelona drinking water treatment plant corresponding to nonylphenolic compounds (MRM mode: $219 \rightarrow 133$ and $219 \rightarrow 147$ for detection of NP, $\mathrm{NPE}_{1} \mathrm{C}$, and $\mathrm{NPE}_{2} \mathrm{C} ; 277 \rightarrow 219$ for $\mathrm{NP}_{1} \mathrm{EC}$ and $321 \rightarrow 219$ for $\mathrm{NP}_{2} \mathrm{EC}$ ).

\section{Mass Spectrometry}

A bench-top triple quadrupole mass spectrometer Quattro LC from Micromass (Manchester, UK) equipped with a pneumatically assisted electrospray probe and a Z-spray interface was used for this study. Capillary voltage was set at $-2.8 \mathrm{kV}$, extractor lens $7 \mathrm{~V}$ and RF lens $0.6 \mathrm{~V}$. The source and desolvation temperatures were 150 and $350{ }^{\circ} \mathrm{C}$, respectively. The nitrogen ( $99.999 \%$ purity) flows were optimized at $50 \mathrm{~L} / \mathrm{h}$ for the cone gas and $540 \mathrm{~L} / \mathrm{h}$ for desolvation gas. For each analyte the values of the voltages applied to the cone, focusing lenses, collision cell, and quadrupoles were optimized by continuous infusion of a standard solution $(1 \mu \mathrm{g} / \mathrm{mL})$ via a syringe infusion pump Kd Scientific 100 (Boston, MA) at a constant flow-rate of 20 $\mu \mathrm{L} / \mathrm{min}$. All ESI mass spectral data were acquired with Masslynx NI software (version 3.5).

MS scans. For one stage MS scans the cone voltage was varied from -10 to $-50 \mathrm{~V}$ according to the type of experiment performed and analyte studied. Full-scan mass spectra were recorded between $\mathrm{m} / \mathrm{z} 30$ and 500, with scan duration of $1 \mathrm{~s} / \mathrm{scan}$ and an interscan time of $0.1 \mathrm{~s}$.
MS/MS scans. The cone voltage was set to a value, which resulted in maximum abundance of the pseudo molecular ion (see Table 1). The argon collision gas was maintained at a pressure of $5.8 \times 10^{-3}$ mbar. The optimum collision energy was chosen after performing MS/MS product ion scans on $[\mathrm{M}-\mathrm{H}]^{-}$over a range of energies between 10 and $50 \mathrm{eV}$. The electron multiplier was set at $600 \mathrm{~V}$. For experiments performed in MRM mode scan time was $1 \mathrm{~s} / \mathrm{scan}$, and the dwell time ranged from 50 to $200 \mathrm{~ms}$, depending on the number of transition channels monitored (from 10 to 20).

\section{Quantification}

Quantitative analyses were done in MRM mode. The extent of ion suppression of MS signal was determined using 4-nonyloxy benzoic acid as an internal standard. The results (see Discussion) showed very limited signal reduction (less than 15\% for sludge and negligible for water samples), thus the quantification was performed using external calibration.

Initially, a series of injections of target compounds in the concentration range from $1 \mathrm{ng} / \mathrm{mL}$ to $10 \mu \mathrm{g} / \mathrm{mL}$ was used to determine the linear concentration range. Calibration curves were generated using linear regres- 
(a)

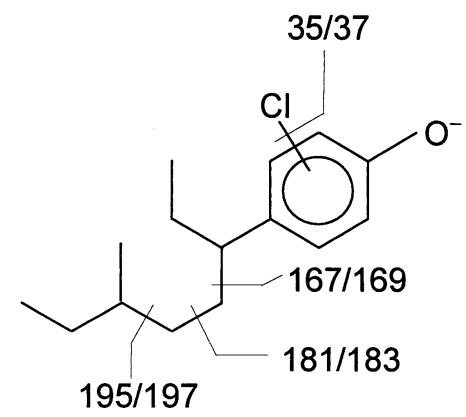

(b)

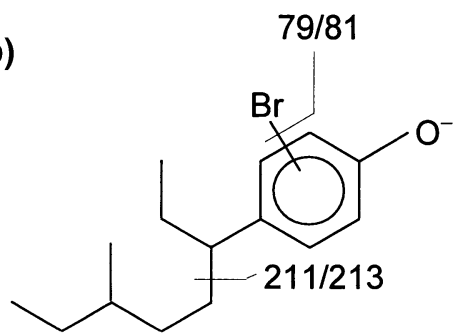

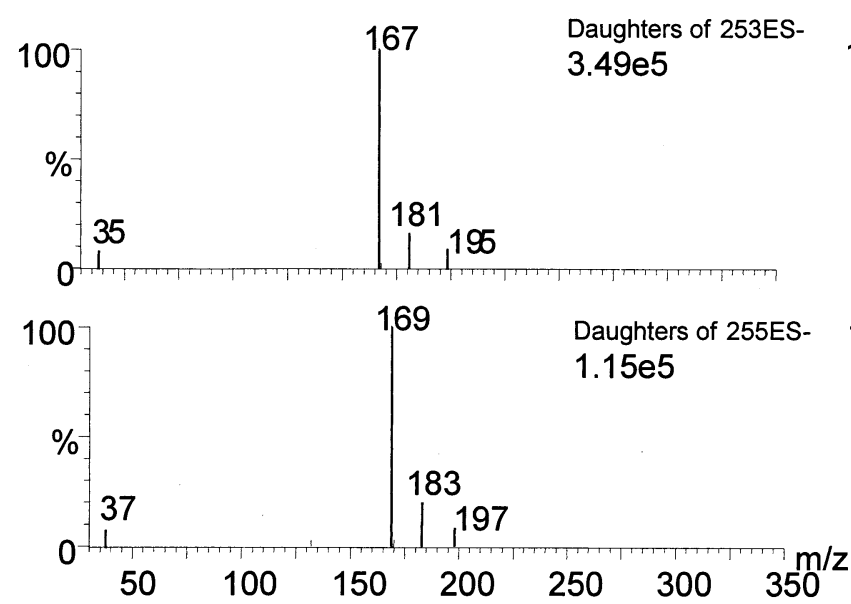

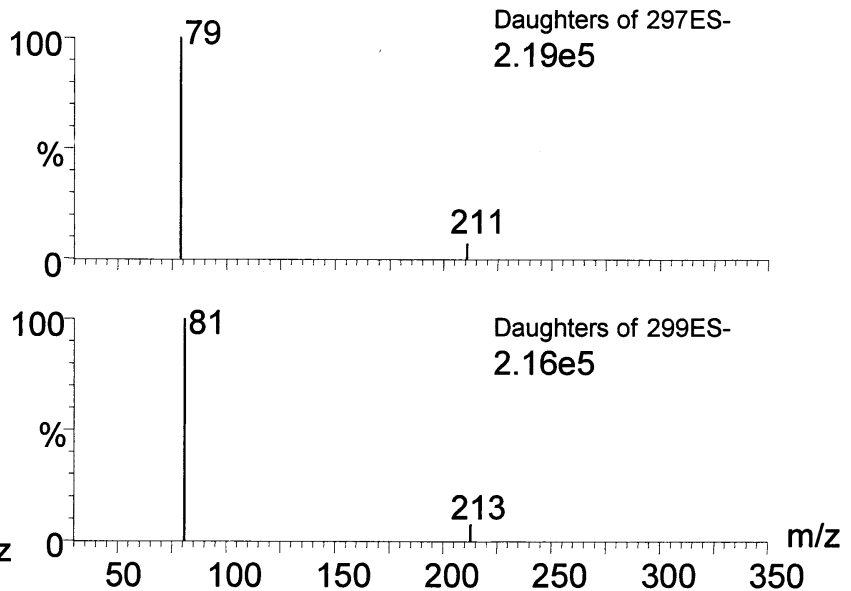

Figure 3. CID spectra and the proposed fragmentation pattern of (a) CINP (precursor ions $\mathrm{m} / \mathrm{z} 253$ and 255) and (b) BrNP (precursor ions $\mathrm{m} / \mathrm{z} 297$ and 299) obtained at collision energy of $30 \mathrm{eV}$. Note: The exact branching of the alkyl chain is unknown and the alkyl isomer shown here is just one of several possibilities.

sion analysis and over the established concentration range $(0.01-1 \mu \mathrm{g} / \mathrm{mL})$ gave good fits $\left(r^{2}>0.990\right)$. Five-point calibration was performed daily, and the possible fluctuation in signal intensity was checked by injecting a standard solution at two concentration levels after each 8-10 injections.

\section{Results and Discussion}

\section{Mass Spectrometry-Optimization of Experimental Conditions}

A preliminary study was carried out using the single quadrupole mode under full-scan conditions and the negative ionization. The cone voltage was adjusted to give the maximum abundance of deprotonated molecule $\left[\mathrm{M}-\mathrm{H}^{-}\right.$, which were chosen as precursor ions in further MS-MS experiments, performed with the purpose of finding the best instrumental conditions for the identification of target compounds.

NP and NPECs. The product ion scan of $[\mathrm{M}-\mathrm{H}]^{-}$for NP evidenced fragmentation of the side chain of deprotonated molecule (Figure 1), resulting in sequential loss of $\mathrm{CH}_{2}$ groups $(\mathrm{m} / \mathrm{z} 14)$, down to specie with $\mathrm{m} / \mathrm{z} 93$. The most abundant fragments with $\mathrm{m} / \mathrm{z} 133$ and 147 resulted from the loss of $\mathrm{C}_{6} \mathrm{H}_{14}$ and $\mathrm{C}_{5} \mathrm{H}_{12}$, respectively.
The product ion spectra of deprotonated molecule at $m / z 277$ (for $\mathrm{NPE}_{1} \mathrm{C}$ ) and $m / z 321$ (for $\mathrm{NPE}_{2} \mathrm{C}$ ), showed the intense signal at $\mathrm{m} / \mathrm{z} 219$, corresponding to $\left[\mathrm{M}-\mathrm{CH}_{2} \mathrm{COO}-\mathrm{H}\right]^{-}$and $\left[\mathrm{M}-\mathrm{CH}_{2} \mathrm{CH}_{2} \mathrm{OCH}_{2} \mathrm{COO}-\mathrm{H}\right]^{-}$, respectively, as reported previously by other authors [2, 22]. Additional fragments at $\mathrm{m} / \mathrm{z} 133$ and 147 were formed by the fragmentation on the side chain, as described above for NP. Thus, specific transitions at $\mathrm{m} / \mathrm{z}$ $277 \rightarrow 219$ and $\mathrm{m} / z 321 \rightarrow 219$ could be used to monitor $\mathrm{NPE}_{1} \mathrm{C}$ and $\mathrm{NPE}_{2} \mathrm{C}$, respectively, while MRM channels at $\mathrm{m} / \mathrm{z} 219 \rightarrow 133$ and $\mathrm{m} / \mathrm{z} 219 \rightarrow 147$ are characteristic for both NP and NPECs, and could be used to monitor all these compounds: However, in the latter case good chromatographic separation is essential, as depicted in Figure 2.

Halogenated NP and NPECs. Owing to the presence of chlorine and bromine atoms in the molecules, halogenated derivatives yielded a characteristic pattern of isotopic doublet signals, which was a highly diagnostic fingerprint for this group of compounds.

The main fragmentation process of CINP was similar to those observed for NP. The predominant reaction was the side chain fragmentation that resulted in sequential loss of $14 \mathrm{Da}$, with the most abundant fragments at $\mathrm{m} / z 167$ for ${ }^{35} \mathrm{Cl}$ and $\mathrm{m} / z 169$ for ${ }^{37} \mathrm{Cl}$ with the 

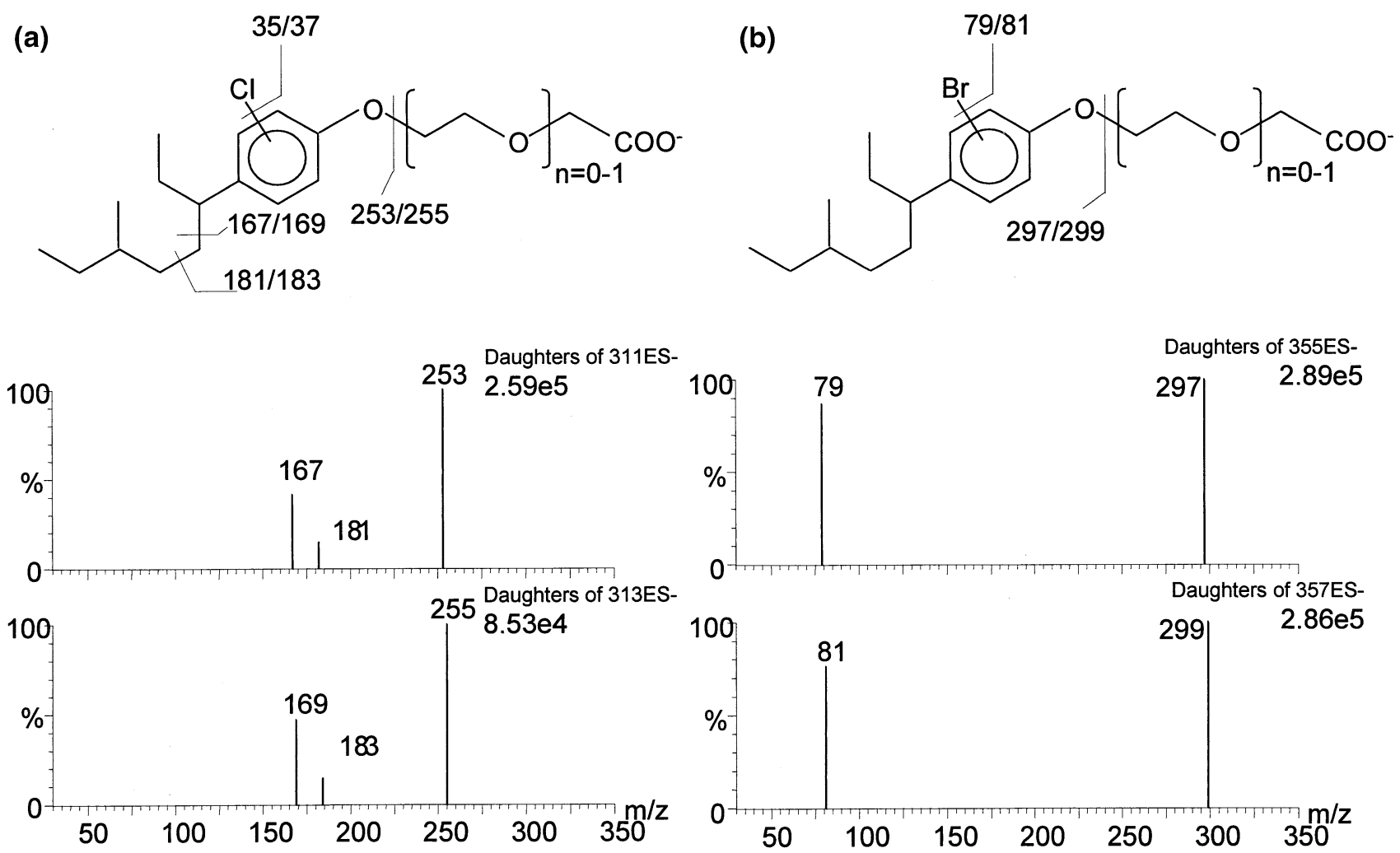

Figure 4. CID spectra and the proposed fragmentation pattern of (a) $\mathrm{ClNPE}_{1} \mathrm{C}$ (precursor ions $\mathrm{m} / \mathrm{z}$ 311 and 313) and (b) BrNPE $_{1} \mathrm{C}$ (precursor ions $\mathrm{m} / z 355$ and 357) obtained at collision energy of $30 \mathrm{eV}$. Note: The exact branching of the alkyl chain is unknown and the alkyl isomer shown here is just one of several possibilities.

relative ratio of intensities of 3.03 (Figure 3a). Fragment corresponding to $[\mathrm{Cl}]^{-}$was produced only when sufficient collision energy was applied. The intensity of this ion was not very pronounced, but nevertheless remained useful for the identification of chlorinated NP.

The brominated NP showed a markedly different fragmentation pathway (Figure 3b). At collision energy of $40 \mathrm{eV}$ the product ion spectra of $\operatorname{BrNP}(\mathrm{m} / z$ 297/299) yielded intense signals at $\mathrm{m} / \mathrm{z} 79$ and 81 corresponding to the $[\mathrm{Br}]^{-}$(ratio of isotopes 1.02), while the fragmentation of the side chain was suppressed and resulted just in a low-intensity fragment at $\mathrm{m} / \mathrm{z} 211 / 213$ produced after the loss of $\mathrm{C}_{6} \mathrm{H}_{14}$.

For halogenated $\mathrm{NPE}_{1} \mathrm{Cs}$ and $\mathrm{NPE}_{2} \mathrm{Cs}$ (Figure 4) the predominant reaction was loss of $\mathrm{CH}_{2} \mathrm{COO}$ and $\mathrm{CH}_{2} \mathrm{CH}_{2} \mathrm{OCH}_{2} \mathrm{COO}$, respectively, that resulted in intense signals at $\mathrm{m} / \mathrm{z} 253 / 255$ for CINPECs and $\mathrm{m} / \mathrm{z}$ 297/299 for BrNPECs. Further fragmentation yielded the same ions as described above for halogenated NPs, i.e., $\left[{ }^{79} \mathrm{Br}\right]^{-}$and $\left[{ }^{81} \mathrm{Br}\right]^{-}$for brominated NPECs and $\mathrm{m} / \mathrm{z}$ $167 / 169$ and $\mathrm{m} / \mathrm{z} 181 / 183$ for CINPECs. Such difference in the mechanism of fragmentation of chlorinated and brominated compounds is presumably the consequence of the lower energy of a $\mathrm{Br}-\mathrm{C}_{6} \mathrm{H}_{5}$ (benzene) bond compared to a $\mathrm{Cl}-\mathrm{C}_{6} \mathrm{H}_{5}$ bond.

BrNPECs yielded $[\mathrm{Br}]^{-}$at low collision energies (10 $\mathrm{eV}$ ), as shown in Figure $5 \mathrm{a}$ for $\mathrm{BrNPE}_{2} \mathrm{C}$, while
CINPECs produced $[\mathrm{Cl}]^{-}$only at higher collision energy $(50 \mathrm{eV})$ (Figure $5 \mathrm{f})$. At collision energy of $50 \mathrm{eV}$ the $\mathrm{m} / \mathrm{z} 79 / 81$ ion was the sole fragment ion observed for $\mathrm{BrNPE}_{2} \mathrm{C}$, while chlorinated analog showed, in addition to $m / z 167 / 169$, fragments at $m / z 131$ and $m / z 145$. These two fragments, observed as product ions of both ${ }^{35} \mathrm{ClNPE}_{2} \mathrm{C}$ and ${ }^{37} \mathrm{ClNPE}_{2} \mathrm{C}$, respectively, did not show characteristic isotopic pattern and were tentatively assigned as fragments formed by the cleavage of ethoxycarboxylated moiety, chlorine and by the cleavages in the alkyl moiety.

From the observed fragmentation pathways the dominant dissociation reaction channels were chosen (Table 1). The cone voltage of each transition was optimized to a value that gave the maximum abundance of the precursor ion, whereas the collision energy was set to a value that resulted in the maximal intensity of the product ion. Generally, deprotonated molecules where chosen as precursor ions, with the exception of $\mathrm{NPE}_{2} \mathrm{C}$ and halogenated $\mathrm{NPE}_{2} \mathrm{Cs}$. Even at low cone voltages $(5-10 \mathrm{~V})$, in-source CID was obtained for these compounds and their spectra displayed low abundance of deprotonated molecules. Thus, for these compounds the most intense MRM channels were those monitoring the fragmentation of "the first generation" products (e.g., $219 \rightarrow 133$ for $\mathrm{NPE}_{2} \mathrm{C}, 297 / 299 \rightarrow 79 / 81$ for $\mathrm{BrNPE}_{2} \mathrm{C}$, and 253/255 $\rightarrow$ 167/169 for $\mathrm{ClNPE}_{2} \mathrm{C}$ ). 

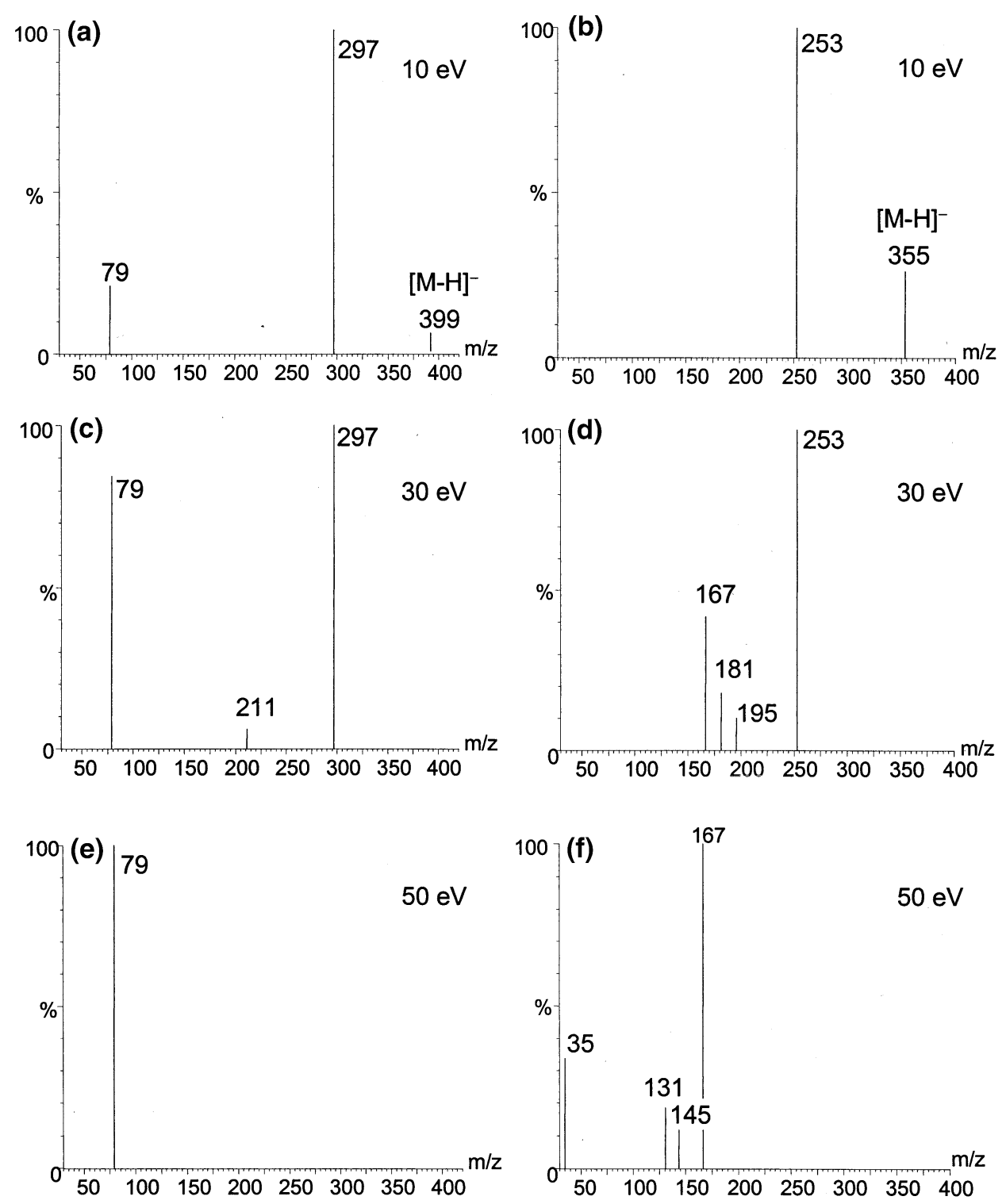

Figure 5. Product ion scans of $\mathrm{XNPE}_{2} \mathrm{C}$ obtained at 10,30 , and $50 \mathrm{eV}:(\mathbf{a}),(\mathbf{c})$, and $(\mathbf{e}){ }^{79} \mathrm{BrNPE}_{2} \mathrm{C}$ (precursor ion $\mathrm{m} / \mathrm{z} 399)$; (b), (d), and (f) ${ }^{35} \mathrm{ClNPE}_{2} \mathrm{C}$ (precursor ion $\mathrm{m} / \mathrm{z} 355$ ).

Positive identification criterion of the target compounds was based on: (1) LC retention time of the analyte compared to that of a standard $( \pm 2 \%)$, (2) the ratio of abundances of two specific precursor ion $\rightarrow$ product ion transitions (within $10 \%$ of the ratios obtained for the standard). Additionally, for halogenated compounds a highly diagnostic criteria was the abundance ratio of characteristic isotopes $\left({ }^{79} \mathrm{Br}:{ }^{81} \mathrm{Br}=1.02\right.$; ${ }^{35} \mathrm{Cl} \cdot{ }^{37} \mathrm{Cl}=3.03$ ) and for each transition reaction two specific channels, corresponding to two isotopes, were monitored and the ratio of their abundances calculated.

High selectivity of the MS-MS detection of halogenated nonylphenolic compounds is shown in Figures 6 and 7, which display extracted MRM chromatograms for chlorinated and brominated compounds, respectively, detected in water and sludge samples from
DWTP of Barcelona. A specificity of MRM mode permitted identification and quantification of halogenated NPECs, thus obviating isobaric interference of $\mathrm{CINPE}_{1} \mathrm{C}$ and $\mathrm{C}_{11}$ LAS (both having a base ion at $\mathrm{m} / \mathrm{z} 311$ ) observed using a LC-MS in selected ion monitoring (SIM) mode [6]. Note that broad and, in some cases multiple peaks, observed, e.g., for brominated compounds (Figure 7), reflect the multitude of isomers arising from the different branching of the nonyl entity and probably co-existence of different isomers of the benzene ring, i.e., $2-\mathrm{NP}$, which makes up to $10 \%$ of NP in industrial blends, and consequently different position of bromine and chlorine, respectively.

Other MS-MS modes, such as the precursor ion scan and neutral loss scan, were found to be less useful MS/MS scanning modes as they were 5 to 10 times less 

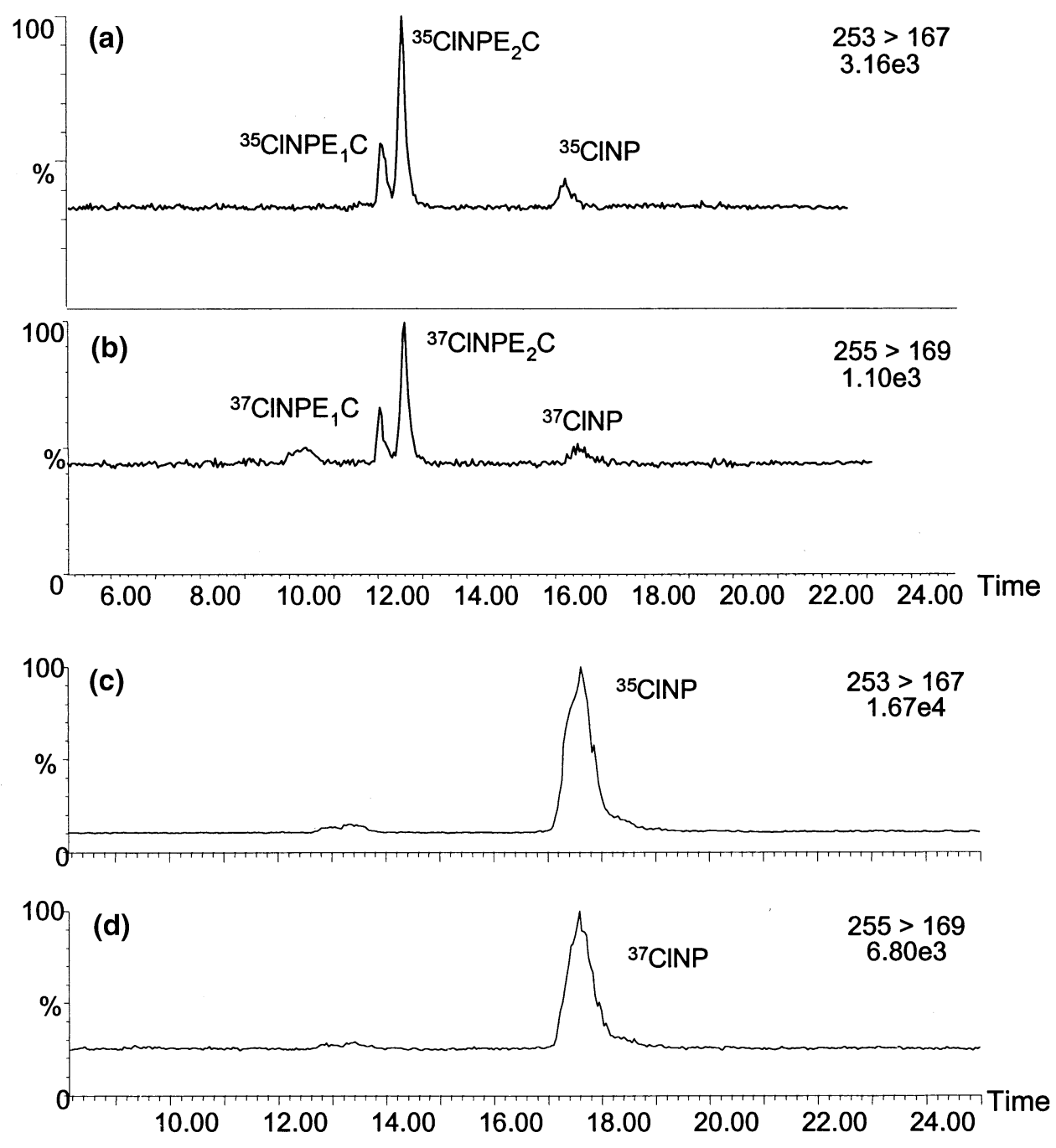

Figure 6. Detection of chlorinated nonylphenolic compounds in prechlorinated water [traces (a) and (b)] and flocculation sludge [traces (c) and (d)] from Barcelona drinking water treatment plant. (MRM mode: $253 \rightarrow 167$ and $255 \rightarrow 169$ for detection of ${ }^{35} \mathrm{Cl}$ and ${ }^{37} \mathrm{Cl}$-nonylphenolic compounds, respectively).

sensitive than product ion MS-MS. The precursor ion scan of the $m / z 133$ yielded the $[\mathrm{M}-\mathrm{H}]^{-}$ions of the respective $\mathrm{NP}, \mathrm{NPE}_{1} \mathrm{C}$, and $\mathrm{NPE}_{2} \mathrm{C}$, together with small "isotopic" peaks one to several mass units higher. However, an acceptable mass chromatographic response was only obtained for nonylphenolic compounds, when present at concentrations higher than 0.5 $\mu \mathrm{g} / \mathrm{L}$. For less abundant halogenated compounds precursor ion scan of $m / z 79 / 81$ for brominated compounds and precursor ion scans of $\mathrm{m} / \mathrm{z} 167 / 169$ and $35 / 37$ for chlorinated compounds were not applicable to realworld samples due to low sensitivity.

\section{Quantitative Analysis}

Matrix effect. One of the problems to be solved when analyzing trace organics in complex matrices by LCMS-(MS) is suppression of the analyte signal caused by high concentration of matrix components. The use of an internal standard can compensate, over a limited retention time window, for signal irreproducibility and correct quantitative data. However, it cannot compensate for the overall sensitivity reduction. Another approach to cope with matrix effect and to avoid an erroneous quantitation is aimed at the reduction of matrix components prior to the LC-MS-(MS) analysis applying a selective extraction and improved sample clean-up. Although the later strategy is laborious, it is still the most direct mean to avoid the loss of sensitivity.

Analytical procedure (SPE for water samples and PLE with SPE clean-up for sludge samples), applied in this work, yielded rather clean extracts that produced low background MS noise, as described in details elsewhere [24]. The extent of ion suppression was checked by adding an internal standard (4-nonyloxy benzoic acid) to all extracts and monitoring the transition reaction from $\mathrm{m} / \mathrm{z} 263[\mathrm{M}-\mathrm{H}]^{-}$to $\mathrm{m} / \mathrm{z} 92$ (retention time $\left.t_{R}=14.7 \mathrm{~min}\right)$. In comparison to the signal 

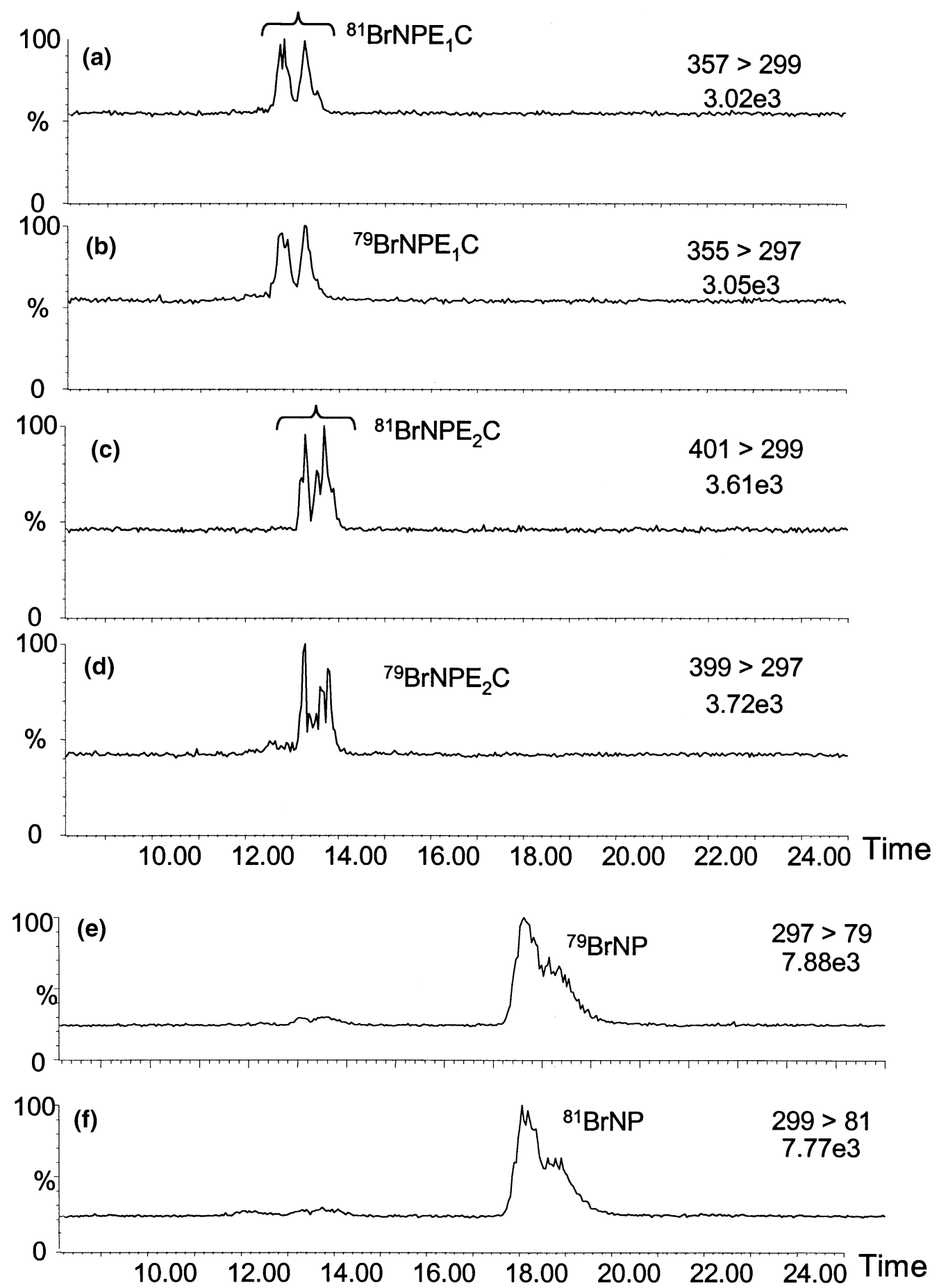

Figure 7. Detection of brominated nonylphenolic compounds in prechlorinated water [traces (a)-(d)] and flocculation sludge [traces (e) and (f)] from Barcelona drinking water treatment plant. MRM mode: (a) $357 \rightarrow 299$ and (b) $355 \rightarrow 297$ for $\mathrm{BrNPE}_{1} \mathrm{C}$; (c) $401 \rightarrow 299$ and (d) $399 \rightarrow 297$ for $\mathrm{BrNPE}_{2} \mathrm{C}$; (e) $297 \rightarrow 79$ and (f) $299 \rightarrow 81$ for BrNP.

intensity obtained in a standard solution (methanol), the flocculation sludge was the only sample that showed a reduced value (limited to 10 to $15 \%$ of ion suppression for all analyzed samples), while less complicated matrices (river water and drinking water) showed negligible loss of sensitivity.
Validation Parameters. Recoveries obtained using LCMS-MS (MRM) were similar to those previously reported for LC-MS (SIM) [6, 24]. SPE of target analytes from water samples combined with LC-MS-MS detection yielded recoveries from 72 to $98 \%$ (see Table 2), whereas for solid samples PLE followed by SPE extract 
Table 2. Instrumental detection limits (LOD $\left.{ }_{\text {inst }}\right)$ of LC-MS and LC-MS-MS, method detection limits (LOD method), and recoveries of combined SPE-LC-MS-MS for the analysis of target compounds in water samples and PLE-LC-MS-MS for solid samples

\begin{tabular}{|c|c|c|c|c|c|c|}
\hline \multirow[b]{2}{*}{ Compound } & \multicolumn{2}{|c|}{$\operatorname{LOD}_{\text {inst }}(\mathrm{pg}$ injected) } & \multicolumn{2}{|c|}{$\mathrm{LOD}_{\text {method }}$} & \multicolumn{2}{|c|}{ Recovery, \% (RSD, $n=3$ ) } \\
\hline & LC-MS (SIM) & $\begin{array}{l}\text { LC-MS-MS } \\
\text { (MRM) }\end{array}$ & $\begin{array}{l}\text { Water samples } \\
(\mathrm{ng} / \mathrm{L})^{\mathrm{a}}\end{array}$ & $\begin{array}{l}\text { Sludge samples } \\
\qquad(\mu \mathrm{g} / \mathrm{kg})^{\mathrm{b}}\end{array}$ & $\begin{array}{c}\text { Water samples } \\
\text { SPE-LC-MS- } \\
\text { MS }\end{array}$ & $\begin{array}{l}\text { Sludge samples } \\
\text { PLE-LC-MS-MS }\end{array}$ \\
\hline NP & 60 & 10 & 1 & 0.5 & $85(5)$ & $81(9)$ \\
\hline XNP & 50 & 15 & 2 & 1.0 & $\begin{array}{l}72 \text { (7) CINP } \\
73 \text { (7) BrNP }\end{array}$ & $\begin{array}{l}60 \text { (14) CINP } \\
64 \text { (11) BrNP }\end{array}$ \\
\hline $\mathrm{NPE}_{1} \mathrm{C}$ & 100 & 30 & 2 & 1.5 & $98(5)$ & $78(8)$ \\
\hline $\mathrm{XNPE}_{1} \mathrm{C}$ & 150 & 50 & 2 & 1.5 & $\begin{array}{l}90 \text { (6) } \mathrm{CINPE}_{1} \mathrm{C} \\
92 \text { (7) } \mathrm{BrNPE}_{1} \mathrm{C}\end{array}$ & $\begin{array}{l}71 \text { (12) } \mathrm{CINPE}_{1} \mathrm{C} \\
75 \text { (9) } \mathrm{BrNPE}_{1} \mathrm{C}\end{array}$ \\
\hline $\mathrm{NPE}_{2} \mathrm{C}$ & 100 & 30 & 2 & 1.5 & $88(4)$ & $68(10)$ \\
\hline $\mathrm{XNPE}_{2} \mathrm{C}$ & 200 & 50 & 2 & 1.5 & $\begin{array}{l}84 \text { (6) } \mathrm{CINPE}_{2} \mathrm{C} \\
79 \text { (7) } \mathrm{BrNPE}_{2} \mathrm{C}\end{array}$ & n.d. \\
\hline
\end{tabular}

aSPE preconcentration factor 1000; 20 MRM channels (for other conditions see Experimental part).

${ }^{b}$ PLE, preconcentration factor 2; 20 MRM channel. \%n.d. not determined.

clean-up and LC-MS-MS detection resulted in recoveries of 60 to $81 \%$ of target compounds. The relative standard deviation $(n=3)$ for water analysis was below $7 \%$ and for sludge below $14 \%$. Intra-day variability of calibration curve slopes was minimal $(<5 \%)$, while inter-day variability of daily calibration curve slopes over 1 week period ranged from 5 to $10 \%$ depending on the analyte.

The comparison of instrumental detection limits (LOD ${ }_{\text {inst }}$ ) obtained using LC-MS and LC-MS-MS in SIM and MRM mode, respectively, and method detection limits (LOD method $_{\text {) }}$ (MRM mode) are shown in Table 2. The LODs were based on the peak-to-peak noise of the baseline near the analyte peak obtained by analyses of a standard solution $\left(\mathrm{LOD}_{\text {inst }}\right)$ and real-samples ( $\left.\mathrm{LOD}_{\text {method }}\right)$, respectively, and on minimal value of signal-to-noise ratio of 3 . The method LODs refer to SPE-LC-MS-MS procedure for water samples, based on a preconcentration factor of 1000, and PLE-LC-MS-MS for sludge samples (preconcentration factor 2). Values of $\mathrm{LOD}_{\text {inst }}$ obtained by LC-MS-MS were approximately 3-6 times lower than by LC-MS (SIM). The detection limits of the method proposed here for the analysis of target compounds in water samples fell down to 1-2 $\mathrm{ng} / \mathrm{L}$ and in sludge samples ranged from 0.5 to 1.5 $\mu \mathrm{g} / \mathrm{kg}$, which is significant improvement in comparison to LODs reported previously for GC-MS [18] and LC-MS [6].

\section{Analysis of Real Samples}

The feasibility of LC-MS-MS method for the analysis of halogenated and non-halogenated NP and NPECs was evaluated by analyzing samples from DWTP Sant Joan Despí in Barcelona. The waterworks, with the daily production of $300,000 \mathrm{~m}^{3}$ of drinking water, are situated at the Llobregat River downstream of a densely industrialized area. The whole river basin receives effluents from more than 30 WWTPs, which results in poor quality of the water entering to DWTP. Moreover, the specificity of the Llobregat River is a high concentration of bromide ions (average $0.7 \mathrm{mg} / \mathrm{L}$, maximum 1.2 $\mathrm{mg} / \mathrm{L}$ in 2000) [25] that arises from salt mine activities in the upper course of the river. As a consequence, it was already reported that treated (tap) water contains rather high concentration of brominated disinfection by-products [26].

NP and NPECs were found in the Llobregat River water entering the water treatment plant in concentrations of $1.5,2.0$, and $2.9 \mu \mathrm{g} / \mathrm{L}$ for $\mathrm{NP}, \mathrm{NPE}_{1} \mathrm{C}$ and the

Table 3. Concentrations found DWTP (Barcelona, Spain) samples

\begin{tabular}{|c|c|c|c|c|c|c|c|}
\hline \multirow[b]{2}{*}{ Compound } & \multicolumn{6}{|c|}{ Concentration in water (ng/L) } & \multirow{2}{*}{$\begin{array}{c}\text { Flocculation } \\
\text { sludge }(\mu \mathrm{g} / \mathrm{kg})\end{array}$} \\
\hline & Raw water & Prechlorination & Sand filter & Ozonation & Carbon filter & Chlorination & \\
\hline NP & 1500 & 240 & 220 & 250 & 160 & 92 & 150 \\
\hline $\mathrm{NPE}_{1} \mathrm{C}$ & 2000 & 1640 & 1600 & 65 & 30 & 12 & 7.0 \\
\hline $\mathrm{NPE}_{2} \mathrm{C}$ & 2900 & 1960 & 2200 & 76 & 35 & 10 & 20 \\
\hline BrNP & n.d. & 17 & 19 & $<5$ & n.d. & n.d. & 105 \\
\hline CINP & n.d. & 9 & 12 & $<5$ & n.d. & n.d. & 145 \\
\hline $\mathrm{BrNPE}_{1} \mathrm{C}$ & n.d. & 120 & 130 & 57 & 21 & $<5$ & n.d. \\
\hline $\mathrm{CINPE}_{1} \mathrm{C}$ & n.d. & 14 & 19 & 13 & 5 & $<5$ & n.d. \\
\hline $\mathrm{BrNPE}_{2} \mathrm{C}$ & n.d. & 316 & 353 & 217 & 52 & 10 & 13 \\
\hline $\mathrm{CINPE}_{2} \mathrm{C}$ & n.d. & 45 & 60 & 26 & $<5$ & $<5$ & 7.5 \\
\hline
\end{tabular}

n.d. - not detected 
most abundant $\mathrm{NPE}_{2} \mathrm{C}$, respectively, whereas their halogenated analogs were not detected as expected (Table 3 ). The following treatment process consists of prechlorination, flocculation with aluminum sulfate, sand filtration, groundwater dilution, ozonation, granular activated carbon filtration and a final chlorination. During the prechlorination steps, NP and NPECs were found to transform to halogenated derivatives. Both, brominated and chlorinated NP and NPECs were detected in prechlorinated water in concentrations up to $315 \mathrm{ng} / \mathrm{L}$, being $\mathrm{BrNPE}_{2} \mathrm{C}$ the most abundant specie. The main part of these compounds, as well as of their precursors were removed by ozonation and subsequent activated carbon filtration. After final chlorination, in the treated water leaving the DWTP non-halogenated compounds were detected at trace levels $(85,12$, and $10 \mathrm{ng} / \mathrm{L}$ for $\mathrm{NP}, \mathrm{NPE}_{1} \mathrm{C}$, and $\mathrm{NPE}_{2} \mathrm{C}$, respectively) indicating the efficient removal of these compounds (95\% of NP and more than $99 \%$ of acidic metabolites). Halogenated derivatives were identified but their concentrations never exceeded $10 \mathrm{ng} / \mathrm{L}$.

The flocculation sludge (daily production $30,000 \mathrm{~kg}$ dry matter) was found to accumulate hydrophobic halogenated compounds and their precursors. NP, brominated and chlorinated NPs were found in concentrations of 150,105 , and $145 \mu \mathrm{g} / \mathrm{kg}$, respectively. Acidic, polar metabolites were found in concentrations up to 20 $\mu \mathrm{g} / \mathrm{kg}$.

\section{Conclusions}

This work presents for the first time the application of liquid chromatography-tandem mass spectrometry to the analysis of halogenated nonylphenolic compounds and their precursors. MS-MS study of target compounds showed characteristic fragmentation pattern for each group of compounds that provided sufficient structural information and permitted the election of specific transition channels for their identification.

In addition to the advantages related to the quantification in MRM mode (high sensitivity and selectivity) the method allowed determination of isobaric target compounds (e.g., $\mathrm{BrNPE}_{1} \mathrm{C}$ and $\mathrm{CINPE}_{2} \mathrm{C}$ ) and elimination of interference of co-eluting isobaric no-target compounds (e.g., $\mathrm{C}_{11}$ LAS). The method yielded very low detection limits: low ng/L level in water samples and low $\mu \mathrm{g} / \mathrm{kg}$ level in sludge samples, thus providing a reliable and robust tool that can be used for routine analysis of estrogenic NP, NPECs, and their halogenated derivatives in aqueous and solid samples.

\section{Acknowledgments}

The work has been supported by the EU Project P-THREE (EVK1-CT-2002-00116) and by the Spanish Ministerio de Ciencia y Tecnologia (PPQ2002-10945-E). AD acknowledges a Ph.D. fellowship from Fundació Agbar. MP acknowledges the "Ramon y Cajal" contract from the Spanish Ministry of Science and Technol- ogy. The authors thank Merck for supplying the SPE cartridges and LC columns.

\section{References}

1. Ahel, M.; Giger, W.; Koch, M. Behavior of Alkylphenol Polyethoxylate Surfactants in the Aquatic Environment. I. Occurrence and Transformation in Sewage Treatment. Water Res. 1994, 28, 1131-1142.

2. Jonkers, N.; Knepper, T. P.; de Voogt, P. Aerobic Biodegradation Studies of Nonylphenol Ethoxylates in River Water Using Liquid Chromatography-Electrospray Tandem Mass Spectrometry. Environ. Sci. Technol. 2001, 35, 335-340.

3. Di Corcia, A.; Constantino, A.; Crescenzi, C.; Marinoni, E.; Samperi, R. Characterization of Recalcitrant Intermediates from Biotransformation of the Branched Alkyl Side Chain of Nonylphenol Ethoxylate Surfactants. Environ. Sci. Technol. 1998, 32, 2401-2409.

4. Di Corcia, A.; Cavallo, R.; Crescenzi, C.; Nazzari, M. Occurrence and Abundance of Dicarboxylated Metabolites of Nonylphenol Polyethoxylate Surfactants in Treated Sewages. Environ. Sci. Technol. 2000, 34, 3914-3919.

5. Ventura, F.; Figueras, A.; Caixach, J.; Espadaler, I.; Romero, J.; Guardiola, J.; Rivera, J. Characterization of Polyethoxylated Surfactants and Their Brominated Derivatives Formed at the Water Treatment Plant of Barcelona by GC/MS and FAB Mass Spectrometry. Water Res. 1988, 22, 1211-1217.

6. Petrovic, M.; Diaz, A.; Ventura, F.; Barceló, D. Simultaneous Determination of Halogenated Derivatives of Alkylphenol Ethoxylates and Their Metabolites in Sludges, River Sediments, Surface, Drinking and Waste Waters by Liquid Chromatography-Mass Spectrometry. Anal. Chem. 2001, 73, 58865895.

7. Ventura, F.; Caixach, J.; Figueras, A.; Espadaler, I.; Fraisse, D.; Rivera, J. Identification of Surfactants in Water by Fast Atomic Bombardment Mass Spectrometry. Water Res. 1989, 23, 11911203.

8. Ventura, F.; Caixach, J.; Romero, J; Espadaler, I.; Rivera, J. New Methods for the Identification of Surfactants and Their Acidic Metabolites in Raw and Drinking Water: FAB MS and MS/ MS. Water Sci. Tech. 1992, 25, 257-264.

9. Reinhard, M.; Goodman, N.; Mortelmans, K. E. Occurrence of Brominated Alkylphenol Polyethoxy Carboxylates in Mutagenic Wastewater Concentrates. Environ. Sci. Technol. 1982, 16, 351-362.

10. Fujita, M.; Ike, M.; Mori, K.; Kaku, H.; Sakaguchi, Y.; Asano, M.; Maki, H.; Nishihara, T. Behavior of Nonylphenol Ethoxylates in Sewage Treatment Plants in Japan-Biotransformation and Ecotoxicity. Water Sci. Technol. 2000, 42, 23-30.

11. Servos, M. R. Review of the Aquatic Toxicity, Estrogenic Responses, and Bioaccumulation of Alkylphenols and Alkylphenol Polyethoxylates. Water Qual. Res. J. Canada 1999, 34, 123-177.

12. Ahel, M.; Giger, W. Partitioning of Alkylphenols and Alkylphenol Polyethoxylates Between Water and Organic Solvents. Chemosphere 1993, 26, 1471-1478.

13. Jobling, S.; Sheahan, D.; Osborne, J. A.; Matthiessen, P.; Sumpter, J. P. Inhibition of Testicular Growth in Rainbow Trout (Oncorhynchus Mykiss) Exposed to Estrogenic Alkylphenolic Chemicals. Environ. Toxicol. Chem. 1996, 15, 194-202.

14. Jobling, S.; Sumpter, J. P. Detergent Components in Sewage Effluent are Weakly Estrogenic to Fish: An in Vitro Study Using Rainbow Trout (Oncorhynchus mykiss) hepatocytes. Aquat. Toxicol. 1993, 27, 361-372.

15. Maki, H.; Okamura, H.; Aoyama, I.; Fujita, M. Halogenation and Toxicity of the Biodegradation Products of a Nonionic 
Surfactant, Nonylphenol Ethoxylates. Environ. Toxicol. Chem. 1998, 17, 650-654.

16. Requena, V., Petrovic, M., Garcia-Reyero, N., Barceló, D., Hansen, P. D., Piña, B. Estrogenic Potential of Halogenated Derivatives of Nonylphenol Ethoxylatyes and Carboxylates; unpublished.

17. Ventura, F.; Fraisse, D.; Caixach, J.; Rivera, J. Identification of [(Alkyloxy)poleythoxy] Carboxylates in Raw and Drinking Water by MS/MS and Mass Determination Using FAB and Nonionic Surfactant as Internal Standard. Anal. Chem. 1991, 63, 2095-2099.

18. Diaz, A.; Ventura, F.; Galceran, M. T. Development of a Solid-Phase Microextraction Method for the Determination of Short-Ethoxy-Chain Nonylphenols and Their Brominated Analogs in Raw and Treated Water. J. Chromatogr. A 2002, 963, 159-167.

19. Diaz, A.; Ventura, F.; Galceran, M. T. Simultaneous Determination of Estrogenic Short Ethoxy Chain Nonylphenols and Their Acidic Metabolites in Water by an In-Sample Derivatization/Solid Phase Microextraction Method. Anal. Chem. 2002, 74, 3869-3876.

20. Ferguson, P. L.; Iden, C. R.; Brownawell, B. J. Analysis of Alkylphenol Ethoxylate Metabolites in the Aquatic Environ- ment Using Liquid Chromatography-Electrospray Mass Spectrometry. Anal. Chem. 2000, 72, 4322-4330.

21. Ferguson, P. L.; Iden, C. R.; Brownawell, B. J. Distribution and Fate of Neutral Alkylphenol Ethoxylate Metabolites in a Sewage-Impacted Urban Estuary. Environ. Sci. Technol. 2001, 35, 2428-2435.

22. Hao, C.; Croley, T. R.; March, R. E.; Koenig, B. G.; Metcalfe, C. D. Mass Spectrometric Study of Persistent Acid Metabolites of Nonylphenol Ethoxylate Surfactants. J. Mass Spectrom. 2000, $35,818-830$.

23. Stokker, G. E.; Daena, A. A.; Desolms, S. J.; Schultz, E. M.; Smith, R. L.; Cragoe, E. J.; Baer, J. E.; Ludden, C. T.; Russo, H. F.; Scriabine, A.; Sweet, C. S.; Watson, L. S. 2-(Aminomethyl)Phenols, a New Class of Saluretic Agents. J. Med. Chem. 1980, 23, 1414-1427.

24. Petrovic, M.; Lacorte, S.; Viana, P.; Barceló, D. Pressurized Liquid Extraction Followed by LC-MS for the Determination of Phenolic Xenoestrogens in River Sediment. J. Chromatogr. A. 2002, 959, 15-23.

25. AGBAR, Aigues de Barcelona, Internal Report. 2001.

26. Cancho, B.; Ventura, F.; Galceran, M. T. Behavior of Halogenated Disinfection By-Products in the Water Treatment Plant of Barcelona, Spain. Bull. Environ. Contam. Toxicol. 1999, 63, 610-617. 